\title{
Asynchronous Rhythm of Ad4BP/SF-1 and Per2 Expression in Adrenal Tumors of Cushing's Syndrome
}

\author{
Kenji Ohe ${ }^{1 *}$, Tomoko Tanaka ${ }^{2}$, Hiroki Terai ${ }^{1}$, Masayoshi Mori ${ }^{1}$, Yusuke Murata ${ }^{1}$, Munechika Enjoji ${ }^{1}$, Makoto Akashi ${ }^{3}$, \\ Koichi Node $^{3}$ and Toshihiko Yanase ${ }^{2}$ \\ ${ }^{1}$ Department of Pharmacotherapeutics, Faculty of Pharmaceutical Sciences, Japan \\ ${ }^{2}$ Department of Endocrinology and Diabetes Mellitus, Faculty of Medicine, Fukuoka University, Japan \\ ${ }^{3}$ Cardiovascular and Renal Medicine, Saga University Faculty of Medicine, Japan
}

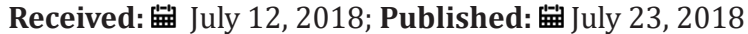

*Corresponding author: Kenji Ohe, Department of Pharmacotherapeutics, Faculty of Pharmaceutical Sciences, Fukuoka University.

\begin{abstract}
The relationship between circadian rhythm and autonomous cortisol secretion of adrenocortical lesions associated with Cushing's syndrome is still unknown. We show here that in Y1 adrenocortical tumor cells, circadian rhythm of Per2 mRNA expression was in a $24 \mathrm{~h}$ manner, while that of steroidogenic-related genes such as P450scc mRNA and Ad4BP/SF-1 mRNA was asynchronous with Per 2 mRNA, compared to normal mouse adrenal primary culture tissue which show synchronized expression of the three genes. Deletion mutants of Ad4BP/SF-1 promoter activity in Y1 cells show that the E-box element functioned in a circadian-like pattern which was abrogated in promoter constructs which lack the E-box. Rhythm of upstream factor-1 (USF-1) mRNA correlated with Ad4BP/SF-1 mRNA expression, which is known to bind the E-box of Ad4BP/SF-1 promoter. Finally, we were able to detect asynchronous rhythm of P450scc, Ad4BP/SF-1 compared with Per2 promoter activity in primary cultured cells derived from adrenocortical lesions associated with Cushing's syndrome. We believe the results presented here a result of tumorigenesis rather than evoking it, but we are certain that the method used here will provide us tools in deciphering the mechanism of tumorigenesis. Thus, we conclude asynchronous expression of Ad4BP/SF-1 and Per2 is in part related to the pathogenesis in adrenocortical lesions of Cushing's syndrome.
\end{abstract}

Keywords: Ad4BP/SF-1; Circadian Rhythm; Adrenal Tumor; Cushing's Syndrome; Tumorigenesis; Steroidogenic; Pathogenesis; Pituitary Gland; Parvocellular Neurons; Hyperplasia

Abbreviations: AD4BP: Adrenal 4 Binding Protein; CREM: Camp Response Element Modulator; DMEM: Dulbecco's Modified Eagle’s Medium; ERK: Extracellular Signal Regulated Kinase; MAPK: Mitogen Activated Protein Kinase; PKA: Protein Kinase A; Per2; Period Homolog 2; RT-PCR: Reverse Transcriptase-Polymerase Chain Reaction; SF-1: Steroidogenic Factor 1; USF: Upstream Stimulatory Factor; GNAS: Gene coding for the stimulatory G-protein $\alpha$ subunit; AIMAH, adrenocorticotropin-independent macronodular Adrenocortical Hyperplasia; PRKAR1A: Protein Kinase Camp Dependent Regulatory Type I $\alpha$ Gene: PPNAD: Primary Pigmented Nodular Adrenocortical Disease

\section{Introduction}

The primary adrenal form of Cushing's syndrome is characterized by ACTH-independent autonomous cortisol secretion from adrenocortical tumors with diminished diurnal rhythm. The normal adrenal gland produces cortisol stimulated by rhythmic secretion of ACTH from the pituitary gland driven by CRH secretion from parvocellular neurons of the paraventricular nucleus of the hypothalamus. Circadian circuits stimulate suprachiasmatic nucleus (SCN) afferents which stimulate CRH secretion [1,2]. In addition to this hypothalamus pituitary adrenal (HPA) axis activity, the peripheral clock of the adrenal gland is known to be activated by light via the suprachiasmatic nucleus-sympathetic nervous system in the absence of ACTH [3]. A continuous loss of rhythmic, but robust and autonomous cortisol secretion from adrenal tumors is ACTH-independent and in some cases ectopic hormone receptors are expressed in the tumors which aberrantly stimulate cortisol secretion [4]. Together with activating mutations of the gene coding for the stimulatory G protein $\alpha$ subunit (GNAS) in adrenocorticotropin independent macronodular adrenocortical hyperplasia (AIMAH) [5] and mutations of protein kinase, Camp dependent, regulatory, type I, $\alpha$ gene (PRKAR1A) in primary pigmented nodular adrenocortical disease (PPNAD), and other accumulating evidence has endorsed the idea that adrenocortical lesions of Cushing's syndrome harbor abnormalities of the cyclic AMP signaling pathway [6].

An extensively detailed evaluation of cortisol level in patients with adrenocortical lesions of Cushing's syndrome has found increased pulsatile secretion and delay in phase shift of $3 \mathrm{~h}$ [7]. This is reminiscent with the Clock mutant mouse where circadian period was $27.3 \mathrm{~h}$ in constant darkness [8]. It remains unclear whether the autonomous secretion of cortisol by the adrenal tumor is brought by 
abnormal rhythm of circadian related genes. Per2 is an important component of the circadian clock system and participates in both input and output pathways of the clock [9]. The blunted response to ACTH of steroid secretion in Per2/Cry1 mutant mice has revealed that the adrenal clock gates the sensitivity to ACTH [10]. Though rate-limiting components of steroidogenesis such as P450scc show no transcriptional circadian rhythm [10], a nuclear factor, Ad4BP/ SF-1 is known to respond to light through the suprachiasmatic nucleus-sympathetic nervous system [3]. Since the mechanism of response of Ad4BP/SF-1 activity to cAMP accumulation is still an open question [11] Ad4BP/SF-1 may be involved in the abnormal steroid secretion in adrenocortical lesions of Cushing's syndrome.

Ad4BP/SF-1 was originally identified as an essential transcription factors that control most steroidogenic genes expression [12]. Ad4BP/SF-1 has also been revealed to be indispensable for the differentiation and development of the adrenals, gonads and particular regions of the pituitary and hypothalamus based on the findings of phenotypes of its knockout mice [13]. Thus, the modulation of the expression level or activity of Ad4BP/SF-1 in adrenals is essential for steroidogenesis. ACTH or PKA has been shown to increase SF-1-mediated transcriptional activity, thus leading to increased steroidogenesis [14]. Several mechanisms for this phenomenon has been proposed, including phosphorylation of SF-1 via PKA itself $[15,16]$ and via its downstream signaling, ERK 1/2 [17] or dephosphorylation mechanism by mitogen activated kinase phosphatase-1 [18] and stimulation of DAX-1 dissociation from SF-1 [14]. Interestingly since cAMP abnormalities have been implicated in the pathogenesis of adrenocortical lesions of Cushing's syndrome [6], PKA related increase of Ad4BP/SF-1 activity may be related with increased cortisol production.

The expression level of Ad4BP/SF-1 in adrenocortical lesions of Cushing's syndrome is controversial; Some reports shows no change of SF-1 [19] but others show a moderate elevation in other studies [20]. In a cultured adrenal cell system, no or little increase of Ad4BP/SF-1 level by PKA stimulation has been demonstrated [21]. However, little is known about the regulatory mechanism of Ad4BP/SF-1 expression in respect of oscillation by circadian rhythm. Such study is particularly interesting in that functioning adrenocortical tumor secretes steroid hormones autonomously and the mechanism has not been well clarified. The circadianrelated gene, Per2, has been implicated in development of cancer [22]. Downregulation of Per2 has been reported in breast cancer [23-25] endometrial cancer [26] lymphoma cell lines and acute myeloid leukemia patient samples [27] chronic myeloid leukemia [28]. Overexpression of Per2 induces cancer cell apoptosis [29].

Since adrenocortical lesions of Cushing's syndrome show autonomous cortisol secretion, it is particularly of interest to investigate whether Per2 is expressed and/or oscillates, and whether it directes oscillation of steroidogenic enzyme genes in these tumors. To our knowledge, a glioma cell line is the only example which shows tumor related circadian rhythm of Per2 promoter activity [30]. In the present study, by using a well-established activation method of circadian rhythm of cultured cells, namely stimulation by $50 \%$ serum shock [31] we tested the rhythmicity of Per2, P450scc and Ad4BP/SF-1 in Y1 adrenocortical tumor cells and primary cultured cells from adrenocortical lesions of Cushing's syndrome and found asynchronous rhythm of expression.

\section{Materials and Methods \\ Cell Culture}

Y1 adrenocortical tumor cells were cultured as previously described [32]. For normal mouse adrenal tissue, the adrenal gland was cut in half (approximately $2 \mathrm{mg}$ ) and incubated in culture medium (DMEM + 10\% serum). Adrenal tumors were obtained from surgically operated (laparotomy) patients under written informed consent and primary cultured as follow. The tumor was cut into small pieces and tissue was finely minced and dispersed to cells by treatment with $0.25 \%$ collagenase at $37^{\circ} \mathrm{C}$ for $30 \mathrm{~min}$ and incubated in culture medium (DMEM + 10\% serum).

\section{Measurement of Corticosterone Level}

Corticosterone level was assessed with the collaboration of SRL Co. Ltd. (Tokyo, Japan) using commercial RIA kits (Diagnostic Products Corp., LA, USA)

\section{Quantitative Real Time RT-PCR and Primers}

Total RNA was extracted by TRizol reagent (Invitrogen). Primers used for amplifying mRNA were as follows. Mouse Per2 (forward; 5'-CAGACTCATGATGACAGAGG-3', reverse;5'GAGATGTACAGGATCTTCCC-3'), mouseP450scc(forward;5' AGGACTTTCCCTGCGCT-3',reverse; 5'-GCATCTCGGTAATGTTGG-3'), mouse Ad4BP/SF-1 (forward; 5'-CCAGGAGTTCGTCTGTCTC-3', reverse; 5'- GATCCCTAATGCAAGGAG-3') mouse USF1 (forward; 5' - GAAAACAGCTGAAACCGAAGAGGGAACAGT-3', reverse; 5'-CATAGACTGAGTGGCAGGGTAACCACTGAT-3'). First-strand complementary DNA was synthesized using $1 \mu \mathrm{g}$ of total RNA as template and PCR was carried out in a Light Cycler (Roche Diagnostics GmbH, Mannheim, Germany) according to the manufacturer's instructions. Threshold values were obtained where fluorescent intensity was in the geometric phase of amplification, as determined with Light Cycler Software Ver.3.5. Expression level at each time point was calibrated to those of $\beta$-actin [33].

\section{Plasmids}

Promoter-luciferase (promoter-luc) constructs of human Ad4BP/SF-1 and human P450scc [32] and mouse Per2 [34] are described previously.

\section{Real Time Monitoring of Luciferase Activity}

Promoter activity was monitered by an in vitro real time monitering system [35]. In brief, transfection by lipofectamine was performed 24h prior serum shock (medium exchanged for serum rich medium (DMEM, supplemented with 50\% serum for two hours and replaced with normal medium (DMEM $+10 \%$ serum thereafter). After serum shock, light emission in the presence of 0.1 $\mathrm{mM}$ luciferin was measured and integrated for $1 \mathrm{~min}$ at intervals of $15 \mathrm{~min}$, with a photomultiplier tube (Hamamatsu Photonics). 


\section{Results}

Steroid Production After Serum Shock in Normal Mouse Adrenal Tissue and Y1 Cells

In order to address whether adrenal tumors possess intrinsic circadian rhythm of de novo steroid hormone synthesis, tissues and cells were stimulated with serum shock for $2 \mathrm{~h}$ and steroid hormones were measured every $4 \mathrm{~h}$ thereafter (Figure 1). Primary culture from normal mice adrenal tissue (approximately $2 \mathrm{mg}$ in $10 \mathrm{ml}$ medium) showed small peaks of corticosterone at 16, 24, $32,40,48,56 \mathrm{~h}$ and an overall (circadian- like) tendency of peaks at 32 and $60 \mathrm{~h}$ (Figure 1A). Corticosterone was undetectable in Y1 cells since these cells do not express steroid 21-hydroxylase [36]. Instead, we measured progesterone secretion from Y1 cells and found an almost linear increase of progesterone up to $32 \mathrm{~h}$, which kept constant up to $60 \mathrm{~h}$. In order to evaluate de novo synthesis (proposing the stability of corticosterone and progesterone are comparable in the culture medium), a $\Delta$ change value (Figure 1) designated as a difference value between present and former value was also calculated. However, even by this method, Y1 cells seemed to show only small bursts of steroid production and no overall tendency of circadian rhythm, raising a possibility that circadian expression of clock related genes which may control steroidogenicenzyme genes may be impaired in tumor cells.
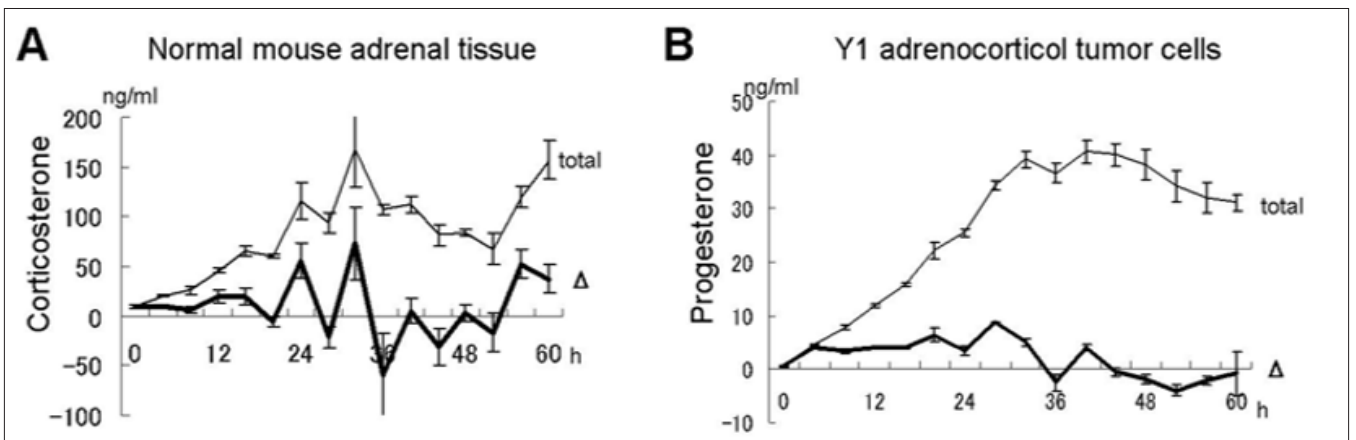

Figure 1: Steroid secretion from normal mouse adrenal gland and Y1 adrenocortical cells after serum shock. En bloc culture of tissue from normal mice adrenal gland (A) and Y1 cells (B) were stimulated with $50 \%$ serum for $2 \mathrm{~h}$ and corticosterone was measured by collecting aliquots of medium every $4 \mathrm{~h}$. Data are mean \pm SEM of 3 experiments. $\Delta$ is difference between previous value.

\section{Per2, Ad4BP/SF-1, P450scc mRNA Expression after Serum Shock}

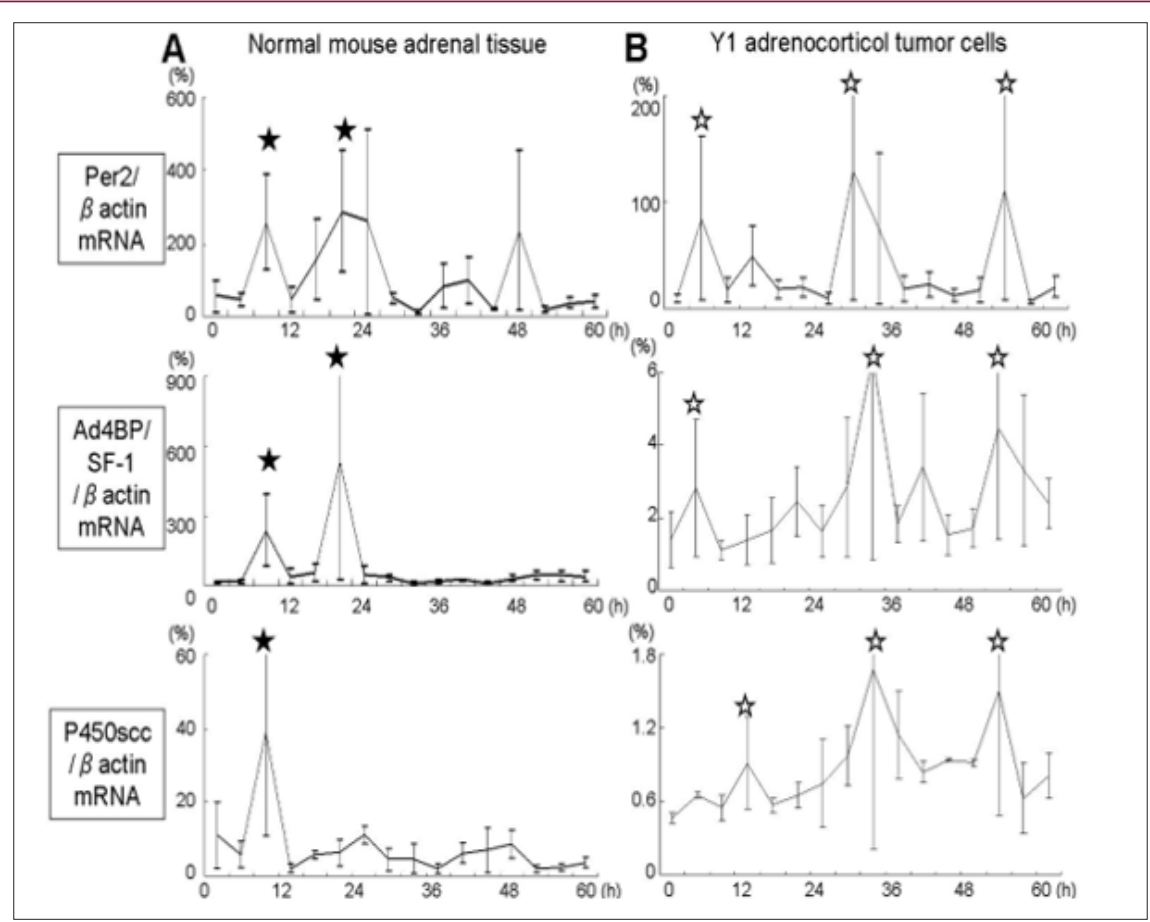

Figure 2: mRNA expression of Per2, Ad4BP/SF-1, P450scc relative to $\beta$-actin after serum shock in en bloc culture of tissue from normal mice adrenal gland (A) and Y1 cells (B) were evaluated. Total RNA at each time point in Fig. 1 was extracted and subjected to real-time RT-PCR. Data are mean \pm SEM of 3 experiments. 
Total RNA was extracted from tissue and cells at the time points which were checked for steroid production (Figure 2). Real time RT-PCR was performed and the relative expression of target gene to $\beta$-actin was examined. Peak expression of Per2, Ad4BP/SF-1, after serum shock in normal adrenal tissue were synchronous, with Per2 mRNA and Ad4BP/SF-1 mRNA peaks at 8 and 20h ( $\star$ in Figure 2A). On the other hand, Y1 cells showed a different profile. While Per2 mRNA showed peak expression at 4, 28, 52h, with $24 \mathrm{~h}$ interval ( 3 Figure 2B, upper), Ad4BP/SF-1 mRNA showed peaks at 4, 32, 56h ( 5 Figure 2B middle) and P450scc mRNA at 12, 36, 52h ( $1 \mathrm{~B}$, lower). Concerning the highest peak, Ad4BP/SF-1 mRNA (32h) was $4 \mathrm{~h}$ later than P450scc mRNA (28h). This asynchronous pattern prompt us to test promoter activity of these three genes in Y1 cells.

\section{Per2, Ad4BP/SF-1, P450scc Promoter Activity After} Serum Shock in Y1 Cells

In order to examine whether the asynchronous mRNA expression of Per2 and Ad4BP/SF-1, P450scc in Y1 cells were due to asynchronous promoter activity, Per2-luc, P450scc-luc (-400bp), Ad4BP/SF-1-luc were transfected and promoter activity was monitered by in vitro real-time luciferase system (Figure 3). In
Y1 cells, Per2-luc showed an interval of $16.5 \mathrm{~h}$ between acrophase (Figure 3A). P450scc-luc showed a dip in promoter activity which restored to the same value after $19.75 \mathrm{~h}$ but continued to increase (Figure 3B). As for Ad4BP/SF-1 promoter we used deletion constructs (-4000bp, -781bp, -480bp, -92bp, -84bp, -77bp) (Figure 3C) [32]. Clear rhythm, with 14-16h interval was seen in -92-luc and longer, which disappeared in -82-luc and -77-luc constructs. An E-box element is known to be located between -87 and -82bp of the human Ad4BP/SF-1 promoter which is the main regulato

ry element [32] to which USF is known to bind [37]. The interval between acrophase of Per- 2 promoter activity was slightly longer in Per-2 promoter compared to Ad4BP/SF-1 promoter activity (16.5h and 14-16h, respectively). Since the E-box element seemed to be responsible for the rhythm seen in Ad4BP/SF-1 promoter, we tested the expression of USF-1 mRNA (Figure 3D) and found it correlated well with that of Ad4BP/SF-1 mRNA (Figure 2B), middle graph compared with Per2 mRNA and Ad4BP/SF-1 mRNA. Though the relationship between the two variables is not linear, correlation value is as follows: Ad4BP/SF-1 mRNA and USF-1 mRNA is 0.738, while Ad4BP/SF-1 mRNA and Per2 mRNA is 0.541.

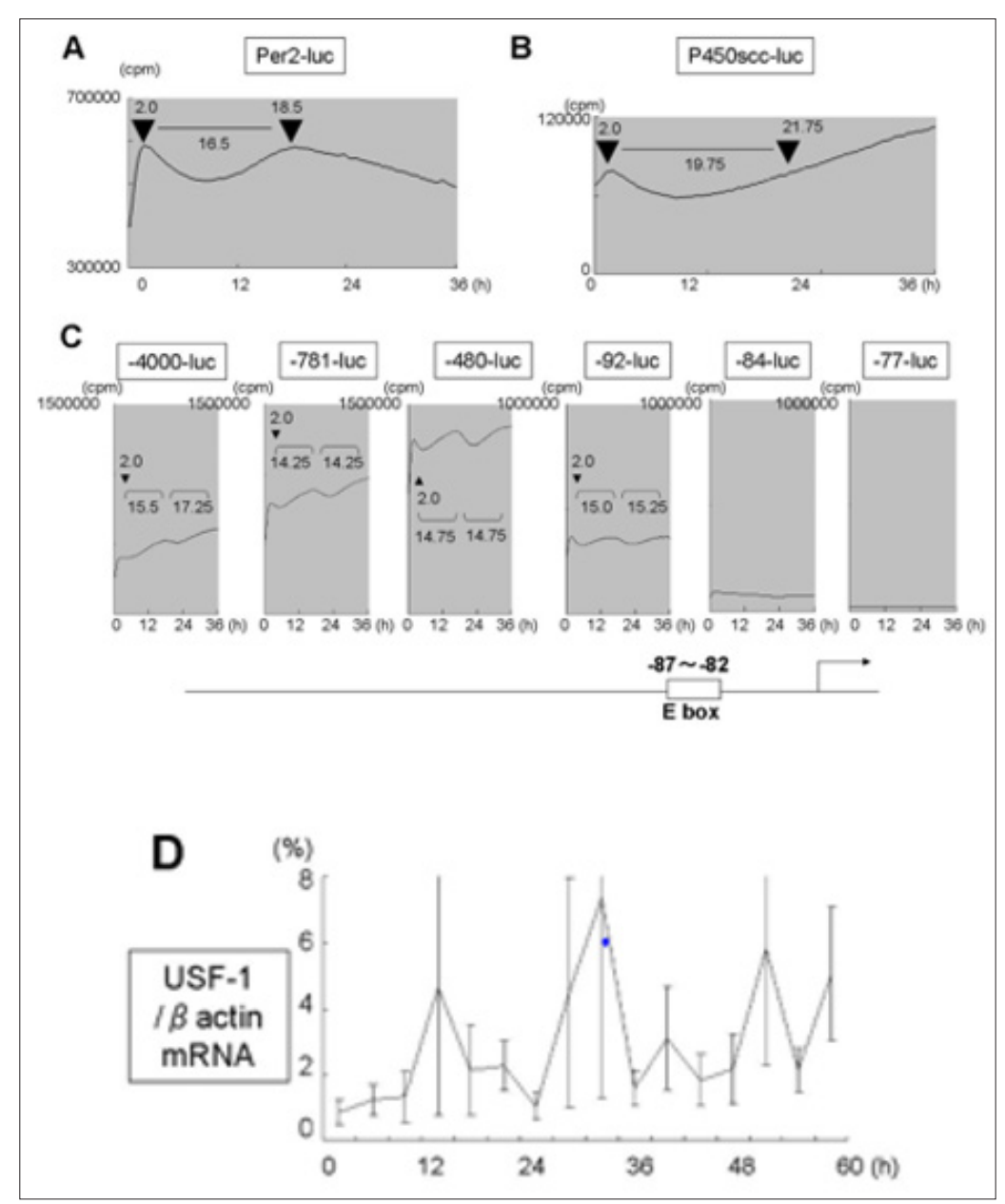

Figure 3: Luciferase activity of Per2 (A), P450scc (B), deletions of Ad4BP/SF-1 (-4000bp, -781bp, -480bp, -92 bp, -84bp, -77bp) (C) promoter after serum shock in Y1 cells and evaluated by real-time luciferase monitoring system. Representative result of four independent experiments is shown.Position of the E-box element is illustrated in cartoon of Ad4BP/SF-1 at bottom. (D) mRNA expression of USF-1 after serum chock in Y1 cells. Total RNA at each time point in Fig. 1 was extracted and subjected to real-time RT-PCR. Data are mean \pm SEM of 3 experiments. 
Per2, Ad4BP/SF-1, P450scc Promoter Activity After Serum Shock in Primary Culture of Adrenocortical Lesions of Cushing's Syndrome

Since Ad4BP/SF-1 promoter exhibited a circadian-like rhythm pattern which was asynchronous with Per2 promoter in Y1 cells, we checked whether primary culture of adrenocortical lesions of Cushing's syndrome had the same feature. Primary culture of non-functioning tumor (for control) showed no rhythm (Figure 4A) while Cushing's syndrome due to primary pigmented nodular adrenocortical disease (PPNAD) (Figure 4B) and adrenal tumor (Figure 4C) showed similar patterns. Per2-luc showed a constant 22-24 interval between peaks of activity, while Ad4BP/SF-1-luc and P450scc-luc showed clearly longer intervals (25-27h) and short intervals (19-23h) appearing in turns which were in inverse correlation.

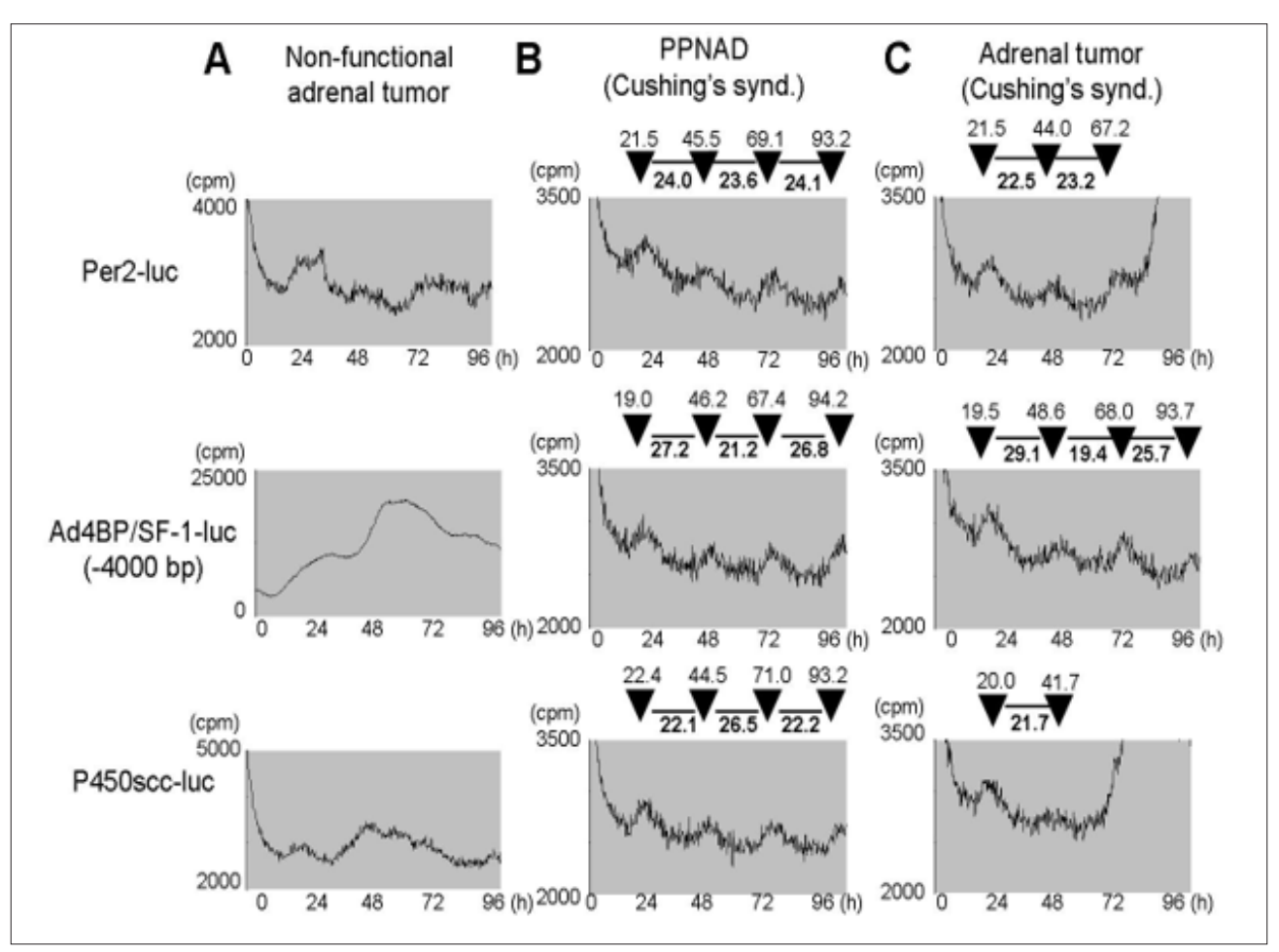

Figure 4: Luciferase activity of Per2, P450scc, Ad4BP/SF-1 (-4000bp) promoter after serum shock in primary culture cells derived from adrenocortical lesions of non-functional adrenal tumor (A), PPNAD of Cushing's syndrome (B) and adrenal tumor of Cushing's syndrome, were evaluated by real-time luciferase monitoring system.

\section{Discussion}

We have shown here that adrenal tumor-derived cells respond to serum shock, which is known to induce circadian expression of various genes [31]. Per2 as well as Ad4BP/SF-1, P450scc genes did respond to serum shock in adrenal tumor-derived cells but these cells could not produce steroid in a circadian fashion. The rhythm of Per2 mRNA expression was synchronized with Ad4BP/SF-1 mRNA in normal mouse adrenal tissue but became asynchronous in Y1 tumor cells. This was confirmed by promoter activity of Per2-luc and Ad4BP/SF-1-luc in Y1 cells and also in primary cultured cells derived from adrenocortical lesions of Cushing's syndrome. The similar expression rhythm of Per2 mRNA and Ad4BP/SF-1 mRNA in normal adrenal tissue compared to similar expression rhythm of USF-1 and Ad4BP/SF-1 in tumor derived tissue, suggested that the E-box element in Ad4BP/SF-1 promoter may be regulated by CLOCK/BMAL [38-40] in normal tissue and by USF-1 in tumors. Confirmation of this would await direct evidence of CLOCK/BMAL heterodimeric protein to regulate $\mathrm{Ad} 4 \mathrm{BP} / \mathrm{SF}-1$ in normal adrenal cells.
Concerning abnormalities of circadian-related genes in adrenocortical lesions of Cushing's syndrome. The identical $3 \mathrm{~h}$ shift found in cortisol level of patients with Cushing's syndrome [7] and clock mutant mouse [8] made us assume abnormal CLOCK gene function in these tumors. But since rhymicity of per2 mRNA was 24h in Y1 cells (Figure 2B, upper panel) and Per2 promoter activity was 22-24 h in primary culture of adrenocortical lesions of Cushing's syndrome, with no $3 \mathrm{~h}$ shift, the possibility of nonfunctional clock protein (Per2 is regulated by CLOCK/BMAL) is low. The sequence of the E-box of Ad4BP/SF-1 promoter is 5'- (-92) AGAGTCACGTGGGGCA(-76)-3' (E-box in bold letters). This is a perfect $\mathrm{E}$ box sequence which is also known as a site of action for CLOCK/BMAL. A study of surrounding sequences of the E-box has found them important for the decision of the E-box to function in a circadian or non-circadian manner [41]. In this context, the E-box of Ad4BP/SF-1 promoter is flanked with sequences resembling that for USF binding, RY-CACGTG-RY (R for purine and Y for pyrimidine) [41] which has already been shown in cell lines [37]. But, since USF factors are ubiquitous, other tissue specific factors have 
been implicated in tissue-specific expression of Ad4BP/SF-1. For example, in the testis, additional factors besides USF factors have been shown to bind the E-box of Ad4BP/SF-1 promoter [42]. In this respect, it seems to be interesting to test a possibility in the near future that CLOCK/BMAL could bind this element in normal adrenal tissue.

Adrenal tumors responsible for Cushing's syndrome are usually in benign forms except that they secrete excess cortisol in an ACTH-independent fashion, that can eventually lead to death if left untreated. Recently, Cushing's syndrome due to ACTH-independent bilateral adrenal tumors seem not to be so rare as previously thought. In fact, growing evidence has shown rare inherited bilateral adrenal tumors and sporadic solitary adrenal tumors being linked to abnormalities in cAMP signaling (reviewed in [6]). cAMP signaling, and circadian rhythm are in close relation, for instance, well known by circadian expression of cAMP inducible factors such as CREM [43] which is also known to be the most highly induced gene in the adrenal gland induced by light [3]. Ad4BP/SF-1 is also induced by light [3] but is not induced by cAMP. Interaction of Ad4BP/SF-1 (or its post-translationally modified form) and CREBbinding protein seems to be important for co-ordinate regulation of steroidogenic enzymes by Ad4BP/SF-1 and cAMP [44]. Thus, the asynchronous correlation of cAMP inducible genes, such as Ad4BP/ SF-1, P450scc and circadian-related gene, Per2, in adrenal tumors of Cushing's syndrome, may give us a clue of the pathogenesis of the loss of circadian rhythm in these tumors.

\section{Acknowledgement}

This work was supported by “Shorei Kenkyu” Project of Fukuoka University to K.O, and also by a Grant-in-Aid for Scientific Research (C) to K.O. (grant 15K10050) from the Ministry of Education, Culture, Sports, Science and Technology of Japan to K.O.

\section{References}

1. Cascio CS, Shinsako J, Dallman MF (1987) The suprachiasmatic nuclei stimulate evening ACTH secretion in the rat. Brain Res 423(1-2): 173178.

2. Szafarczyk A, Ixart G, Malaval F, Nouguier Soule J, Assenmacher I (1979) Effects of lesions of the suprachiasmatic nuclei and of p-chlorophenylalanine on the circadian rhythms of adrenocorticotrophic hormone and corticosterone in the plasma, and on locomotor activity of rats. J Endocrinol 83(1): 1-16.

3. Ishida A, Mutoh T, Ueyama T, Bando H, Masubuchi S, et al. (2005) Light activates the adrenal gland: timing of gene expression and glucocorticoid release. Cell Metab 2(5): 297-307.

4. Lacroix A, Ndiaye N, Tremblay J, Hamet P (2001) Ectopic and abnormal hormone receptors in adrenal Cushing's syndrome. Endocr Rev 22(1): 75-110.

5. Fragoso MC, Domenice S, Latronico AC, Martin RM, Pereira MA, et al. (2003) Cushing's syndrome secondary to adrenocorticotropinindependent macronodular adrenocortical hyperplasia due to activating mutations of GNAS1 gene. J Clin Endocrinol Metab 88(5): 2147-2151.

6. Stratakis CA, Boikos SA (2007) Genetics of adrenal tumors associated with Cushing's syndrome: a new classification for bilateral adrenocortical hyperplasias. Nat Clin Pract Endocrinol Metab 3(11): 748-757.

7. Van Aken MO, Pereira AM, Van Thiel SW, Van Den Berg G, Frolich M, et al. (2005) Irregular and frequent cortisol secretory episodes with preserved diurnal rhythmicity in primary adrenal Cushing's syndrome. J Clin Endocrinol Metab 90(3): 1570-1577.

8. Vitaterna MH, King DP, Chang AM, Kornhauser JM, Lowrey PL, et al. (1994) Mutagenesis and mapping of a mouse gene, Clock, essential for circadian behavior. Science 264(5159): 719-725.

9. Albrecht U, Bordon A, Schmutz I, Ripperger J (2007) The multiple facets of Per2. Cold Spring Harb Symp Quant Biol 72: 95-104.

10. Oster H, Damerow S, Kiessling S, Jakubcakova V, Abraham D, et al. (2006) The circadian rhythm of glucocorticoids is regulated by a gating mechanism residing in the adrenal cortical clock. Cell Metab 4(2): 163173.

11. Val P, Lefrancois Martinez AM, Veyssiere G, Martinez A (2003) SF-1 a key player in the development and differentiation of steroidogenic tissues. Nucl Recept 1(1): 8.

12. Rice DA, Mouw AR, Bogerd AM, Parker KL (1991) A shared promoter element regulates the expression of three steroidogenic enzymes. Mol Endocrinol 5(10): 1552-1561.

13. Luo X, Ikeda Y, Schlosser DA, Parker KL (1995) Steroidogenic factor 1 is the essential transcript of the mouse Ftz-F1 gene. Mol Endocrinol 9(9): 1233-1239.

14. Fan W, Yanase T, Wu Y, Kawate H, Saitoh M, et al. (2004) Protein kinase A potentiates adrenal 4 binding protein/steroidogenic factor 1 transactivation by reintegrating the subcellular dynamic interactions of the nuclear receptor with its cofactors, general control nonderepressed-5/transformation/transcription domain-associated protein, and suppressor, dosage-sensitive sex reversal-1: a laser confocal imaging study in living KGN cells. Mol Endocrinol 18(1): 127-141.

15. Zhang P, Mellon SH (1996) The orphan nuclear receptor steroidogenic factor-1 regulates the cyclic adenosine 3',5'-monophosphate-mediated transcriptional activation of rat cytochrome P450c17 (17 alphahydroxylase/c17-20 lyase). Mol Endocrinol 10(2): 147-158.

16. Carlone DL, Richards JS (1997) Functional interactions, phosphorylation, and levels of 3',5' -cyclic adenosine monophosphate-regulatory element binding protein and steroidogenic factor-1 mediate hormone-regulated and constitutive expression of aromatase in gonadal cells. Mol Endocrinol 11(3): 292-304.

17. Gyles SL, Burns CJ, Whitehouse BJ, Sugden D, Marsh PJ, et al. (2001) ERKs regulate cyclic AMP-induced steroid synthesis through transcription of the steroidogenic acute regulatory (StAR) gene. J Biol Chem 276(37): 34888-34895.

18. Sewer MB, Waterman MR (2003) CAMP-dependent protein kinase enhances CYP17 transcription via MKP-1 activation in H295R human adrenocortical cells. J Biol Chem 278(10): 8106-8111.

19. Shibata H, Ikeda Y, Mukai T, Morohashi K, Kurihara I, et al. (2001) Expression profiles of COUP-TF, DAX-1, and SF-1 in the human adrenal gland and adrenocortical tumors: possible implications in steroidogenesis. Mol Genet Metab 74(1-2): 206-216.

20. Bassett MH, Mayhew B, Rehman K, White PC, Mantero F, et al. (2005) Expression profiles for steroidogenic enzymes in adrenocortical disease. J Clin Endocrinol Metab 90(9): 5446-5455.

21. Nomura M, Kawabe K, Matsushita S, Oka S, Hatano O, et al. (1998) Adrenocortical and gonadal expression of the mammalian Ftz-F1 gene encoding Ad4BP/SF-1 is independent of pituitary control. J Biochem 124(1): 217-224.

22. Fu L, Pelicano H, Liu J, Huang P, Lee C (2002) The circadian gene Period2 plays an important role in tumor suppression and DNA damage response in vivo. Cell 111(1): 41-50.

23. Chen ST, Choo KB, Hou MF, Yeh KT, Kuo SJ, et al. (2005) Deregulated expression of the PER1, PER2 and PER3 genes in breast cancers. Carcinogenesis 26(7): 1241-1246. 
24. Winter SL, Bosnoyan Collins L, Pinnaduwage D, Andrulis IL (2007) Expression of the circadian clock genes Per1 and Per2 in sporadic and familial breast tumors. Neoplasia 9(10): 797-800.

25. Tokunaga $H$, Takebayashi $Y$, Utsunomiya $H$, Akahira JI, Higashimoto $M$, et al. (2008) Clinicopathological significance of circadian rhythm-related gene expression levels in patients with epithelial ovarian cancer. Acta Obstet Gynecol Scand 87(10): 1060-1070.

26. Shih MC, Yeh KT, Tang KP, Chen JC, Chang JG (2006) Promoter methylation in circadian genes of endometrial cancers detected by methylationspecific PCR. Mol Carcinog 45(10): 732-740.

27. Gery S, Gombart AF, Yi WS, Koeffler C, Hofmann WK, et al. (2005) Transcription profiling of C/EBP targets identifies Per2 as a gene implicated in myeloid leukemia. Blood 106(8): 2827-2836.

28. Yang MY, Chang JG, Lin PM, Tang KP, Chen YH, etal. (2006) Downregulation of circadian clock genes in chronic myeloid leukemia: alternative methylation pattern of hPER3. Cancer Sci 97(12) :1298-1307.

29. Hua H, Wang Y, Wan C, Liu Y, Zhu B, et al. (2006) Circadian gene mPer2 overexpression induces cancer cell apoptosis. Cancer Sci 97(7): 589596.

30. Fujioka A, Takashima N, Shigeyoshi Y (2006) Circadian rhythm generation in a glioma cell line. Biochem Biophys Res Commun 346(1): 169-174.

31. Balsalobre A, Damiola F, Schibler U (1998) A serum shock induces circadian gene expression in mammalian tissue culture cells. Cell 93(6): 929-937.

32. Oba K, Yanase T, Ichino I, Goto K, Takayanagi R, et al. (2000) Transcriptional regulation of the human FTZ-F1 gene encoding Ad4BP/ SF-1. J Biochem 128(3): 517-528.

33. Gondo S, Yanase T, Okabe T, Tanaka T, Morinaga H, et al. (2004) SF-1/ Ad4BP transforms primary long-term cultured bone marrow cells into ACTH-responsive steroidogenic cells. Genes Cells 9(12): 1239-1247.

34. Akashi M, Ichise T, Mamine T, Takumi T (2006) Molecular mechanism of cell-autonomous circadian gene expression of Period2, a crucial regulator of the mammalian circadian clock. Mol Biol Cell 17(2): 555565.

\section{ISSN: 2574-1241}

DOI: 10.26717/BJSTR.2018.07.001459

Kenji Ohe. Biomed J Sci \& Tech Res

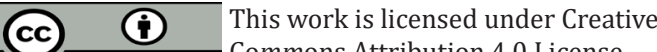

Submission Link: https://biomedres.us/submit-manuscript.php
35. Akashi M, Takumi T (2005) The orphan nuclear receptor RORalpha regulates circadian transcription of the mammalian core-clock Bmal1. Nat Struct Mol Biol 12(5): 441-448.

36. Szyf M, Milstone DS, Schimmer BP, Parker KL, Seidman JG, et al. (1990) Cis modification of the steroid 21-hydroxylase gene prevents its expression in the Y1 mouse adrenocortical tumor cell line. Mol Endocrinol 4(8): 1144-1152.

37. Harris AN, Mellon PL (1998) The basic helix-loop-helix, leucine zipper transcription factor, USF (upstream stimulatory factor), is a key regulator of SF-1 (steroidogenic factor-1) gene expression in pituitary gonadotrope and steroidogenic cells. Mol Endocrinol 12(5): 714-726.

38. Hogenesch JB, Gu YZ, Jain S, Bradfield CA (1998) The basic-helix-loophelix-PAS orphan MOP3 forms transcriptionally active complexes with circadian and hypoxia factors. Proc Natl Acad Sci USA 95(10): 54745479 .

39. Darlington TK, Wager Smith K, Ceriani MF, Staknis D, Gekakis N, et al. (1998) Closing the circadian loop: CLOCK-induced transcription of its own inhibitors per and tim. Science 280(5369): 1599-1603.

40. Gekakis N, Staknis D, Nguyen HB, Davis FC, Wilsbacher LD, et al. (1998) Role of the CLOCK protein in the mammalian circadian mechanism. Science 280(5369): 1564-1569.

41. Munoz E, Brewer M, Baler R (2002) Circadian Transcription. Thinking outside the E-Box. J Biol Chem 277(39): 36009-36017.

42. Daggett MA, Rice DA, Heckert LL (2000) Expression of steroidogenic factor 1 in the testis requires an E box and CCAAT box in its promoter proximal region. Biol Reprod 62(3): 670-679.

43. Foulkes NS, Duval G, Sassone Corsi P (1996) Adaptive inducibility of CREM as transcriptional memory of circadian rhythms. Nature 381: 8385.

44. Monte D, De Witte F, Hum DW (1998) Regulation of the human P450scc gene by steroidogenic factor 1 is mediated by CBP/p300. J Biol Chem 273(8): 4585-4591.

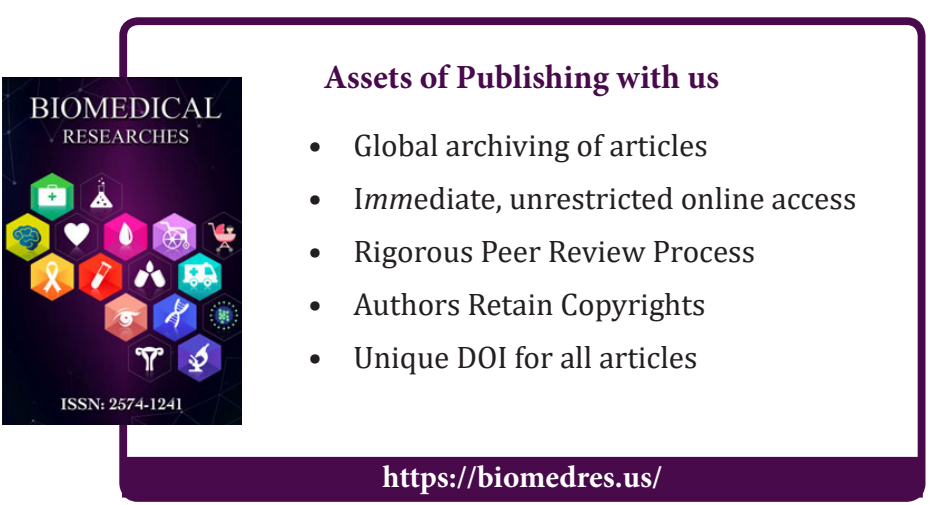

Cite this article: Kenji O, Hiroki T, Masayoshi M, Yusuke M, Munechika E, et al. Asynchronous Rhythm of Ad4BP/SF-1 and Per2 Expression in 